\title{
Extent of Construction Safety in the Engineering Curricula from the Perspec- tive of Practitioners in the MENA Region
}

\section{Dr. Essam K. Zaneldin P.E., United Arab Emirates University}

Dr Essam Zaneldin earned his PhD in 2000 from the University of Waterloo in the area of Construction Engineering and Management. Dr Zaneldin is a professional engineer currently working as an associate professor of Construction Engineering and Management at the Department of Civil and Environmental Engineering, United Arab Emirates University. Dr Zaneldin is also the head of the College of Engineering Requirements Unit at the United Arab Emirates University. In addition to his experience in the academia, Dr Zaneldin has more than thirteen years of work experience in areas related to design, construction supervision, and project management of mega size projects in North America and the Middle East. He has authored and co-authored several journal and conference publications in topics related to engineering education and course management, design coordination, change management, site layout planning, constructability, claims and disputes, and simulation of design and construction operations.

\section{Dr. Amr M.I. Sweedan, UAE University}

Amr Sweedan is an associate professor of Structural Engineering and the Chairman of th Department of Civil and Environmental Engineering at the UAE University. He is a registered professional engineer in the province of Ontario, Canada (P.Eng.). Sweedan earned his Ph.D. in Structural Dynamics from the University of Western Ontario, Canada. He received his M.Sc. and B.Sc. degrees in Structural Engineering from Ain Shams University, Cairo, Egypt. Before joining the UAE University, Sweedan held the position of a Senior Engineer at the head office of Rowan Williams Davies \& Irwin Inc. (RWDI), Consulting Engineers and Scientists, in Guelph, Ontario, Canada. Sweedan areas of research interest include: Modeling and Testing of Solid, Cellular and Castellated Steel Elements; Strengthening of Steel Structures using FRP Laminates; Evaluation of Structural Response to Seismic and Wind Loading; and Design and Behavior of Shell Structures under Hydrodynamic and Hydrostatic Pressures.

\section{Dr. Munjed A. Maraqa, United Arab Emirates University}

Munjed Maraqa is an associate professor and assistant director of the Roadway, Transportation and Traffic Safety Research Center at the UAE University. His research covers a broad range of issues related to modeling environmental systems, water quality, waste management, and traffic safety. Between 20082012, Maraqa acted as an advisor to Al Ain Municipality on the development of an EHS management system for the Building and Construction Sector in Abu Dhabi Emirate. Maraqa holds B.Sc. and M.Sc. degrees in Civil Engineering from the University of Jordan, and a Ph.D. in Environmental Engineering from Michigan State University. 


\title{
Extent of Construction Safety in the Engineering Curricula from the Perspective of Practitioners in the MENA Region
}

\author{
Essam Zaneldin ${ }^{1}$, Munjed Maraqa ${ }^{2}$, and Amr Sweedan ${ }^{3}$ \\ ${ }^{1,2,3}$ Department of Civil and Environmental Engineering, United Arab Emirates University, \\ P.O. Box 15551, Al Ain, United Arab Emirates. \\ ${ }^{1}$ E-mail:essamz@uaeu.ac.ae \\ ${ }^{2}$ E-mail: m.maraqa@uaeu.ac.ae \\ ${ }^{3}$ E-mail: amr.sweedan@uaeu.ac.ae
}

\begin{abstract}
The level of safety implied by the construction industry records world-wide is significantly low compared to other industries. The construction industry has the most dismal record of safety among all industrial segments, with a risk of fatality that is about five times higher than in any other industry. The higher rate of accidents and fatalities in the construction industry could be due to the nature of the work; however, several factors have been identified that could affect construction safety. Among these factors is the provision of construction safety education to engineering students. It is also believed that there is a greater ability to influence safety on a project earlier in the project's life cycle and such ability diminishes as the schedule moves from conceptual design toward start-up. Thus, provision of construction safety education to engineering students will have benefits both for the project design and later in the procurement stage.

Construction safety education for engineering students may involve two main aspects; construction site safety and design for construction safety (DfCS). Progress has been made in the developed countries to incorporate both aspects in the engineering curriculum. However, the extent to which engineering students in the Middle East and North Africa (MENA) region receive construction safety education during their undergraduate study is not known. To assess this extent, a survey was designed and distributed to engineering practitioners in some MENA countries. The survey was also utilized to assess the need for comprising construction safety education in the engineering curriculum. The study showed that about $70 \%$ of the surveyed practitioner engineers did not receive construction safety knowledge during their university education. Of those who did, almost half received such knowledge during internship. Meanwhile, about half of those who received some construction safety education ranked the received level as being "average". Initial results showed that the majority of the surveyed practitioners believe that there is a need for more construction safety education at the university level. The study also suggests some modifications to enhance the current level of construction safety education in the MENA region such as incorporating some topics of DfCS to be included in traditional design courses in order to address this crucial issue.
\end{abstract}




\section{Introduction}

Previous research work showed that there is a considerable high level of risk associated with the construction industry. This risk could reach to as high as five times the risk of fatality in other industrial sectors ${ }^{1,2,3}$. While this observation could be attributed to the nature of construction work, several factors have been identified in the literature that could affect construction safety (see for example the work of Choudhry et al. ${ }^{4}$ and Maraqa and Mohamed ${ }^{5}$ ) including the level of construction safety education provided to engineering students. As a matter of fact, it is more feasible to enhance the level of safety in the project during the early planning and conceptual design stages rather than at the construction stage ${ }^{6}$. As a result, proper coverage of construction safety in the engineering curricula will positively impact the project design and the procurement phase as well. The importance of formal education with regard to construction safety has also been recognized by Davies and Tomasin ${ }^{3}$. While there is a close relationship between education and labor conditions ${ }^{7}$, there is generally a lack of specific education in occupational safety for engineering professionals ${ }^{8}$. It has been suggested that such deficiency can be resolved at the university level. In general, construction safety education for engineering students involves two main aspects; (1) construction site safety and (2) designing for construction safety. While there has been some progress made in the developed countries to incorporate safety in the engineering education, it is not known to what extent the engineering students in the Middle East and North Africa (MENA) region receive safety in their construction-related courses.

The main objective of this study is to determine, using a questionnaire survey, what construction safety knowledge practitioners have received at university and what safety knowledge they would expect in newly hired engineering graduates. A review of the literature pertinent to the role of engineering education in construction site safety was first presented followed by a brief about design for construction safety. The details of the questionnaire survey was then presented along with the analysis and results of the data received. Based on the results of the survey, the authors proposed modifications to the current engineering curriculum to enhance the level of construction safety education.

\section{Construction Site Safety Education}

The need for construction site safety education is now a consensus issue among construction educators and the industry for its important contribution towards the reduction of the number and costs of accidents. As such, incorporation of construction site safety in university curricula has been the topic of several research studies. In 1995, Suckarieh and Diamantes ${ }^{9}$ surveyed construction management programs in the US that are accredited by the American Council for Construction Education $\left(\mathrm{ACCE}^{10}\right)$. The authors indicated that safety has not influenced construction education to any significant extent. They stated that the time devoted to construction safety for construction engineering students is lacking. The authors found that courses dedicated solely to construction safety existed in only about $50 \%$ of the surveyed construction management programs. The common elements of the lower division safety courses included introduction to the Occupational Safety and Health Act, Occupational Safety and Health Administration (OSHA) Standards, administration in the field, craft education requirements, filing forms and accidents reports, keeping hazardous materials information, and preparing for OSHA inspections. The authors concluded that a plan for formal education in construction safety can be 
either a stand-alone course or integrated into all elements of the curriculum by covering the material in several courses in a coordinated manner.

Coble et al. ${ }^{11}$ conducted a survey to obtain information about the extent that safety was integrated into four-year university-level construction in ACCE-accredited programs in the US. Of the responding programs, $45 \%$ indicated that a course is offered within their curriculum that is wholly devoted to safety. The study also revealed that all the safety courses that are offered address the OSHA standards for construction. Moreover, $75 \%$ of all programs, including those that offer a separate safety course, address construction safety in other courses within the construction program. Gambatese ${ }^{12}$ studied the inclusion of construction safety in both construction and civil engineering programs in the US. All the surveyed programs were either $\mathrm{ABET}^{13}$ - or ACCE-accredited. The author found that none of the responding ABET-accredited civil engineering programs offers a course wholly devoted to safety. This was attributed to the fact that ABET accreditation for civil engineering programs stresses on design and does not require coverage of construction site safety. The author, however, found that construction safety is covered to some extent in other courses in the civil engineering curricula of $64 \%$ of the responding programs.

In the UK, most universities incorporate construction site safety at relevant points throughout the undergraduate civil engineering curriculum as opposed to addressing it in a separate course ${ }^{14}$. AlMufti $^{14}$ suggested that the approach to teaching construction safety should comprise safety as an integral part of all other teaching as opposed to an individual course devoted to the topic.

Pellicer et al. ${ }^{15}$ reported a lack of academic education in construction safety in the civil engineering programs in Spain. To remedy this, the authors suggested adjustment of some courses to incorporate construction safety. The authors also proposed an educational guide in construction safety which introduces the culture of health and safety in the civil engineering curricula. Later, Rubio et al. ${ }^{16}$ analyzed the course requirements of civil engineering programs at eight universities in Spain. The authors found no course specifically devoted to safety and health, but a chapter is dedicated to safety and health is taught within a course on procedures of construction and machinery, but not at all universities. Cortes et al. ${ }^{17}$ conducted a survey to define a framework for including occupational risk-prevention education in the new engineering syllabi in Spain. Survey results indicated that education in occupational risk-prevention is essential for improving the safety culture within a workplace.

\section{Design for Construction Safety}

Designing for construction safety (DfCS) is a process that incorporates hazard analysis at the beginning of a design project. The process does not address methods to make construction safer, but how to make a project safer to build. In other words, safe constructability considers worker safety in the design of a facility rather than the traditional design aspects that focus only on the safety of the "end-user". Engineering measures are then applied to eliminate the hazard or reduce the risk. If the hazard cannot be eliminated, then safety devices are incorporated. If some risk still exists, then warnings, instruction, and training should be used as a last resort. 
Traditionally, designers have been under no obligation to inform contractors of hazards resulting from the design. However, designers could play an important role in ensuring how safety of construction workers is considered during the project design process. Competent designers can draw from their own experience and published information, to comply with the duties of reducing hazards and appreciate the risk in their design. In fact, designing to eliminate or avoid hazards is considered the preferable means for reducing risk in the hierarchy of controls ${ }^{18}$. It should be emphasized that reducing injuries and fatalities and improving worker health are not the only benefits associated with DfCS. Addressing safety in the conceptual or early design stages could yield other measurable benefits such as improved productivity, a decrease in operating costs, avoidance of expensive retrofitting to correct design shortcomings, and significant reductions in injuries, illnesses, and environmental damage.

There is evidence that careful consideration of safety during the design stage could have eliminated or reduced injuries and fatalities in some construction projects ${ }^{19}$. While the merits of DfCS are evident, numerous barriers to its implementation have been cited ${ }^{20}$. Among these barriers are limited availability of tools, guidelines, and procedures for preventive design, and the limited education which engineers receive on issues of construction worker safety and on how to design for safety.

The extent to which the engineering academic programs responded to the need for inclusion of DfCS varies but some progress has been noticed over the last 15 years. Carpenter et al. ${ }^{21}$ reported that the requirements of the accreditation bodies had improved significantly in both approach and detail and that academia had developed good links with industry. The authors recommended that accreditation bodies should request higher education institutions ensure that the external examiner is sufficiently briefed to assess course content and health and safety risk management. Progress in DfCS in the US did not move as fast as it did in the UK. Gambatese ${ }^{12}$ found that DfCS is covered only in less than $7 \%$ of the courses of the surveyed construction programs in the US. Weinstein et al. ${ }^{22}$ indicated that the current political and legal environment in the US rules out any prospect of a safety-in-design requirement being enacted.

\section{Questionnaire Survey}

The MENA countries include a total of 22 countries, namely Algeria, Bahrain, Cyprus, Egypt, Iraq, Iran, Israel, Jordan, Saudi Arabia, Kuwait, Lebanon, Libya, Morocco, Oman, Palestine, Qatar, Sudan, Syria, Tunisia, Turkey, United Arab Emirates, and Yemen. In this study, a questionnaire survey was conducted in order to assess the need for graduating engineers to acquire construction safety education during their study. The survey targeted practitioners (mainly engineers) working in the construction sector in some MENA countries. In some of the survey questions, respondents were asked to choose one answer from a given list. In other questions, respondents were requested to choose all applicable answers from a given list. In the analysis of the results of the former set of questions, the authors will refer to the answers in terms of number of respondents, with the total number of respondents equal to the sample size. However, in the analysis of the second set of questions, the authors will refer to the answers in terms of number of responses, which exceeds the sample size. 
The survey included 17 questions and was divided into two main parts. The first part (Questions 1-9) was intended to identify the extent that engineering graduates from the MENA region received construction safety during their study. The second part of the survey (Questions 10-17) was designed to collect opinions on the importance of incorporating construction safety education in the engineering curriculum. Some of the respondents did not graduate from the MENA region although they work in the region, or have a non-engineering degree from the MENA region. These respondents (graduates of Australia, France, India, Malaysia, Philippines, South Africa, South Korea and UK) were not considered in the analysis of the results of the first part of the survey but were considered in the analysis of the second part. The number of respondents that is considered in the second part of the survey is 401 , while the total number of respondents that were included in the analysis of the first part of the survey is 318 .

The first 5 questions of the survey form collected background information about the respondents including nationality, specialization, university, and country from which they graduated and year of graduation. Questions 6-8 collected information about the type of courses, if any, through which the respondents received construction safety education during their bachelor degree program, while Question 9 requested practitioners to rank the level of construction safety education they received during their undergraduate studies.

Questions 10-12 asked for information regarding the countries the respondents have worked in after graduation, the number of years they have been working in the construction field, and the positions in the field that they have been involved in. Question 13 inquired if the respondent thinks there is a need for more construction safety education at the university level in the region; while Question 14 and 15 asked about the form that could be utilized to offer construction safety knowledge to university students. Question 16 asked if the respondent thinks graduating students should pass a construction health and safety examination by a certified board in the country before being able to practice engineering. Question 17 requested the respondents to indicate (on a scale from 0 to 10) the need for graduating engineers to acquire some stated safety aspects. Fifteen safety aspects were included in the survey, namely incorporation of safety in design courses (SA1), hazard identification/risk assessment (SA2), controlling and preventing hazards (SA3), safety regulations (SA4), record keeping (SA5), general safety and health provisions (SA6), electrical safety (SA7), falls from height protection (SA8), falling objects protection (SA9), personal protective equipment (SA10), materials handling, storage, use and disposal (SA11), working on scaffolds (SA12), cranes, hoists, elevators and conveyors (SA13), excavations/burial under earth falls (SA14), and working/standing on stairways and ladders (SA15).

\section{Safety Education Received}

Figure 1 shows the countries from which the respondents to the survey graduated along with their nationalities. A large portion (about 40\%) of the surveyed practitioners graduated from the UAE. This is attributed to the fact that the authors were able to assign individuals to distribute and collect the survey form in the UAE where they are residing. 


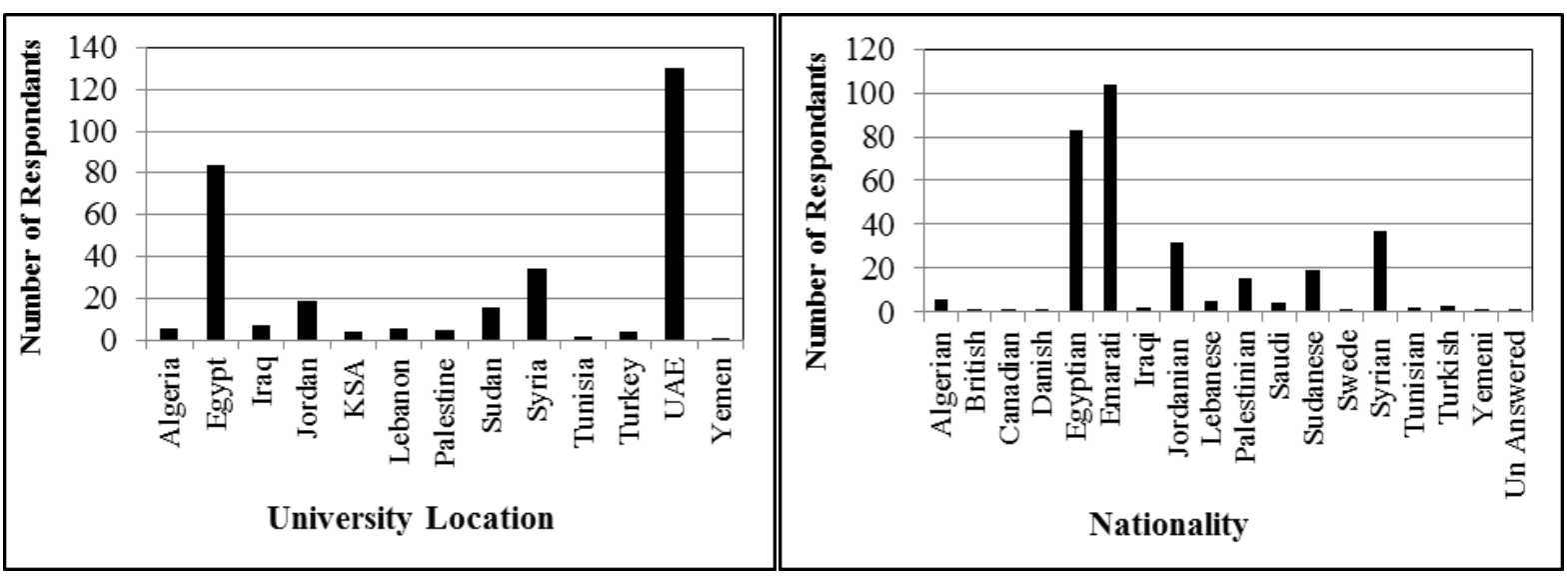

Figure 1: Background Information about the Surveyed Engineers

Some of the surveyed engineers are nationals of countries outside the MENA region but they graduated from universities in the MENA and worked in the region. Also, more than $65 \%$ of the respondents graduated in the year 2000 and after and, as such, the overall opinion of the surveyed engineers is likely to reflect the current situation in terms of construction safety education. It was also found that, $57 \%$ of the surveyed engineers have a degree in civil engineering while $22 \%$ have a degree in architectural engineering. The remaining $(21 \%)$ have a degree in electrical engineering, mechanical engineering, or other engineering disciplines.

When asked if they have taken any construction safety courses during their undergraduate education, $69 \%$ of the respondents answered "No", 30\% answered "Yes", and 1\% did not answer this question. This reflects a deficiency of construction safety education in the curriculum. Those who received construction safety education (97 out of 318) were requested to mark the type of course(s) in which they received safety education. Almost half received it through internship, while some received it through regular university courses (i.e.; core, elective, or capstone courses). Almost half of the respondents ranked the level of safety education they received during their undergraduate studies as being "Average". Meanwhile, about 40\% (representing about $12 \%$ of the whole surveyed practitioners) were satisfied with the level received (Figure 2).

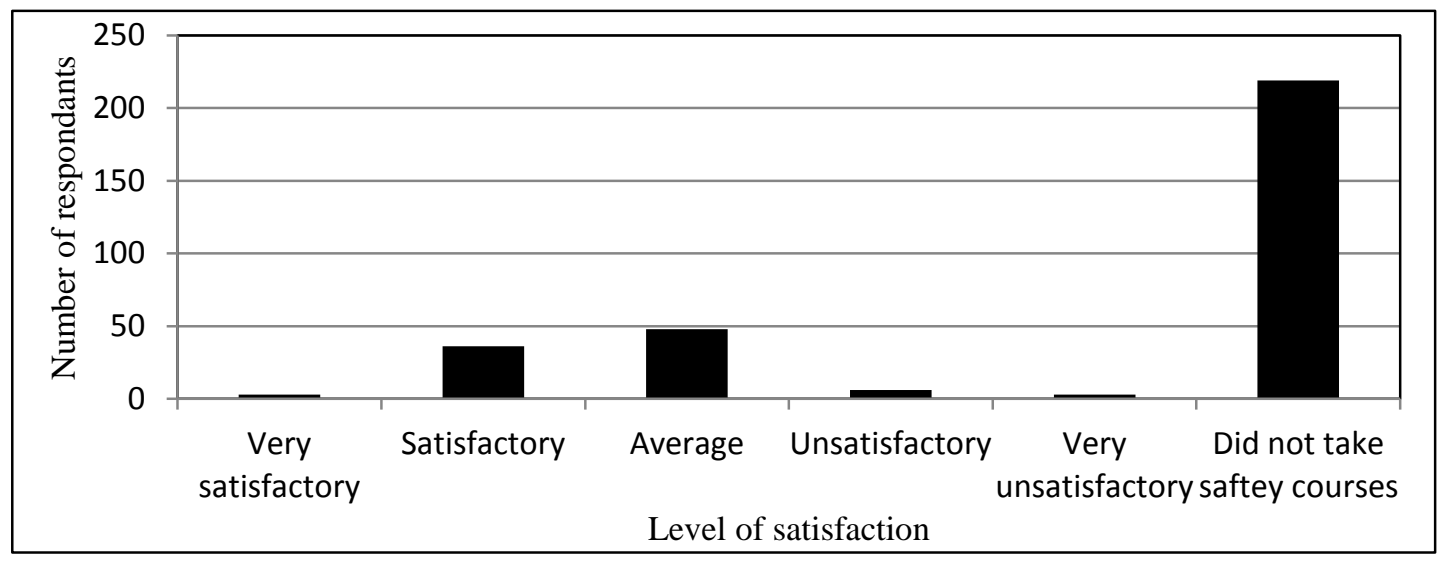

Figure 2: Level of Respondents' Satisfaction with the Construction Safety Education Received 


\section{The Need for Construction Safety Education}

The 401 surveyed practitioners held different positions such as being designers/consultants, project managers, site engineers/supervisors, contractors, developers, and other. Other positions held by some of the respondents include safety specialist, project engineer, quality assurance/quality control specialist, inspector, sales engineer, client/owner, project planning/control, urban planner, surveyor, material engineer, supplier, and temporary work designer. More than $50 \%$ of the surveyed practitioners have 5 years of experience or more in the field. Meanwhile, the surveyed practitioners worked in 18 different countries within the MENA region, as shown in Figure 3.

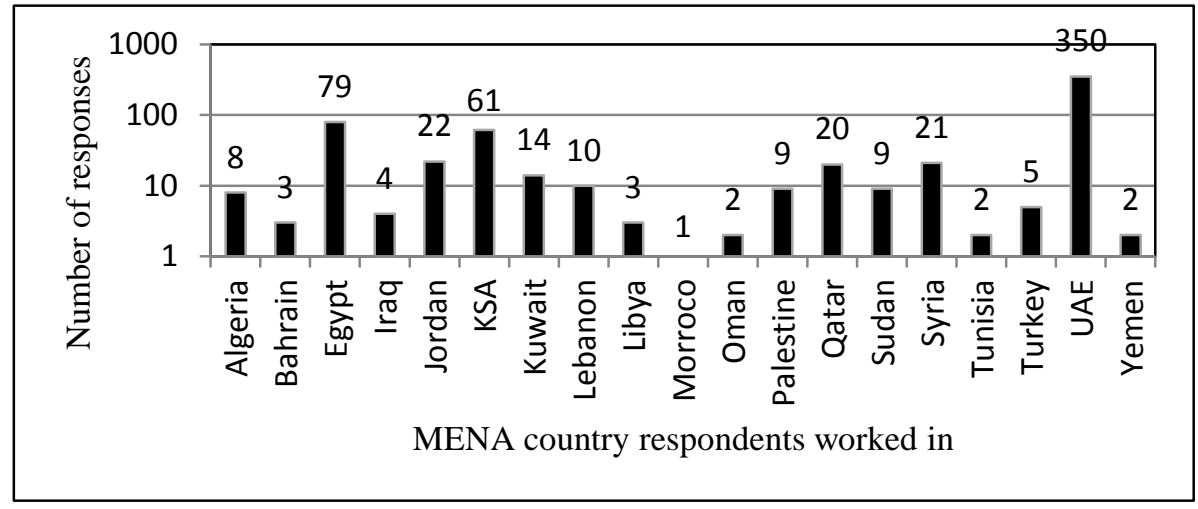

Figure 3: MENA Countries in Which the Respondents Worked

When inquired about the need for more construction safety education at the university level, 85\% of the surveyed practitioners reported "Yes", $6 \%$ indicated "No", $8 \%$ answered "Don't know", and $1 \%$ did not answer the question. On the other hand, the highest number of respondents indicated that construction safety education should be given through internship (Figure 4).

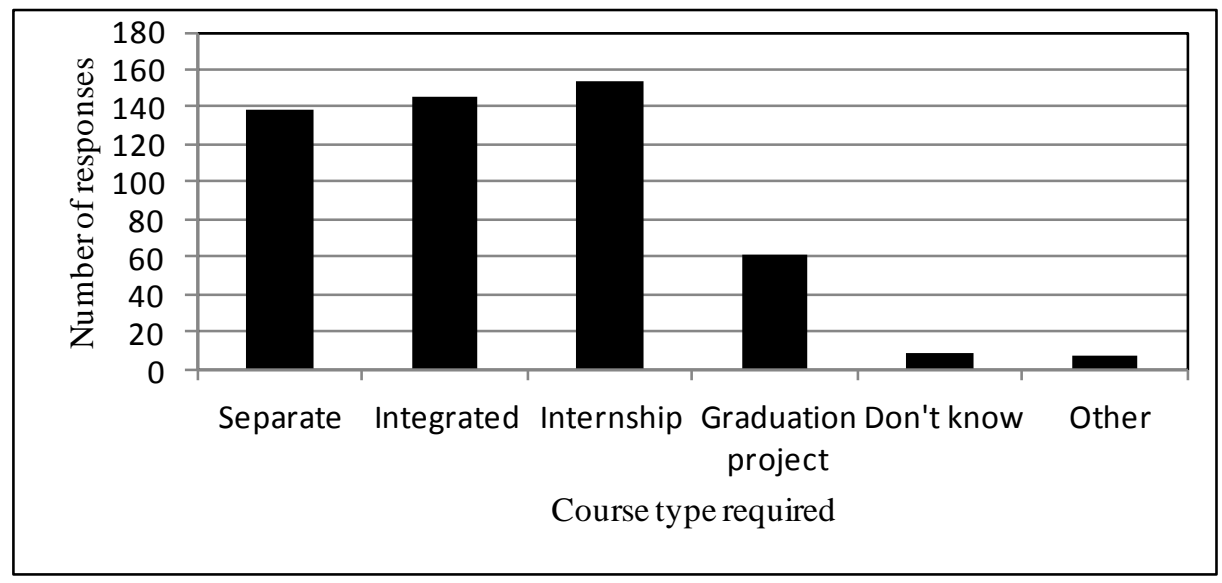

Figure 4: Construction Safety Course Type Based on Practitioners' Feedback

A slightly lesser number indicated that construction safety should be offered as a separate course or integrated within other existing courses. Only 61 respondents indicated that construction 
safety should be given as part of the graduation project course. The practitioners were also asked about their opinion of having graduating students pass a safety examination by a certified body before being able to work. Around 54\% answered "Yes", but a significant proportion (32\%) responded "No", 11\% replied "Don't know", and 3\% did not answer this question.

To plan for inclusion of construction safety education in the curriculum, one needs to know the safety aspects that are important to the program. As such, practitioners were asked to rank 15 suggested construction safety aspects (Figure 5) that should be gained by graduating engineers using a scale of 0 to 10 ( 0 indicates not needed and 10 indicates mostly needed). The suggested safety aspects includes incorporating safety in design courses (SA1), hazard identification/risk assessment (SA2), controlling and preventing hazards (SA3), safety regulations (SA4), record keeping (SA5), general safety and health provisions (SA6), electrical safety (SA7), falls from height protection (SA8), falling objects protection (SA9), personal protective equipment (SA10), materials handling, storage, use and disposal (SA11), working on scaffolds (SA12), cranes, hoists, elevators and conveyors (SA13), excavations/burial under earth falls (SA14), and working on stairways and ladders (SA15). It should be noted that the first 3 safety aspects (SA1-SA3) are related to DfCS, while the other ones (SA4-SA15) are related to site safety.

Figure 5 represents the average score on a scale of $0-10$. The average score of any safety aspect fell in the range of 7.5-8.5, with $95 \%$ confidence limits (shown on the figure) that range from 0.19 to 0.23 . The slight variations in the average score and associated confidence limits of the different safety aspects suggest that all stated aspects are equally important according to the surveyed practitioners. It should be noted that a small fraction $(<3 \%)$ of the surveyed practitioners selected the "don't know" option on any of the listed safety aspects.

Sixty five respondents provided comments in the survey form. Most of these comments were in support of including construction safety in the engineering curriculum. However, respondents' comments differed in the way that safety education should be incorporated (i.e.; as a core course, integrated with other courses, or/and as part of the internship). Some also suggested that students should attend training workshops and seminars conducted by safety professionals.

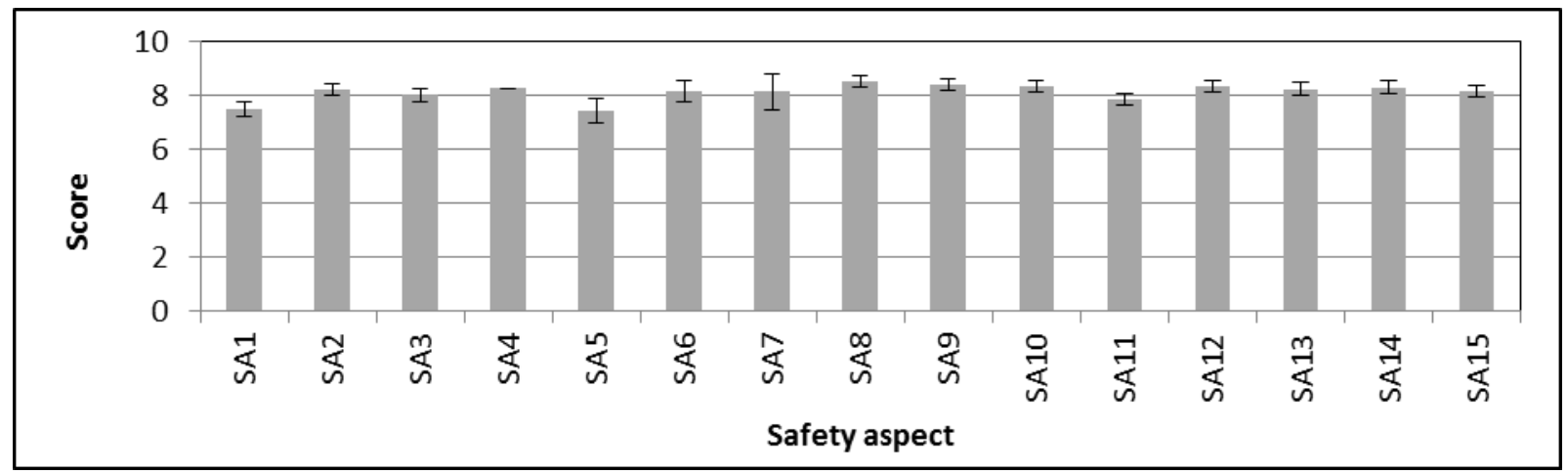

Figure 5: Safety Aspects to be Gained by Graduating Students as Suggested by Practitioners 


\section{Proposed Curriculum Modifications}

Construction safety education for engineering students in the MENA region could be improved by incorporating a core course in the curriculum and by integrating design for construction safety topics in traditional design courses. The additional core course was suggested based on the survey responses received from the practitioners. This core course could be offered to both $\mathrm{CE}$ and $\mathrm{AE}$ students. Based on the review of the literature and the feedback received from the survey respondents on safety aspects SA4 to SA15, it is suggested that the core course contains five main topics including safety analysis, legal issues, safety management, hazards in construction sites and temporary work. Although the suggested "safety analysis" topic was not explicitly included in the safety aspects, the authors suggest to include it as an introductory part in the course to demonstrate records of construction accidents, their types and causes. Moreover, the suggested "temporary work" topic could be included in topic 4 but the authors prefer to make it a separate topic as it was emphasized in the comments recieved by some survey respondents.

The course could be offered either as a 3 credit-hour course covering the five suggested topics or as a 2 credit-hour course covering the first four topics only. In terms of course offering within the study plan, it is recommended that students take the course before their internship and before taking design courses. Field trips should be incorporated as an essential component in this course. Adding this course to the program may require reviewing the entire curriculum in order to accommodate the extra credit hours of the suggested core course. This modification coupled with strict safety regulations imposed in the construction industry would reduce the injury rates as evident in the drop of the fatality injury rate of construction workers which has been observed in the UK in the last 20 years $^{23}$.

The authors also believe that it is crucial to introduce the DfCS principles to senior undergraduate students. The difference between traditional design approach that targets end-user safety and DfCS that addresses safety of workers during construction and maintenance stages should be clearly outlined and explained to students. Nonetheless, DfCS could be incorporated in most of the currently offered traditional design courses. Enhancement of DfCS could also be achieved by making it a requirement in capstone courses (graduation projects), where students demonstrate how the concept is applied during their project design stage.

\section{Conclusions and Recommendations}

The current study assessed the extent to which engineering students at universities in the MENA region receive construction safety education during their undergraduate study. A survey form was designed and distributed to engineering practitioners in the MENA region. The survey was implemented to assess the need for including construction safety education in the engineering curriculum. The study showed that only $30 \%$ of the surveyed practitioners received construction safety education during their university study. Around $50 \%$ of them indicated that they received this knowledge during internship while fewer respondents indicated that they received such knowledge through core and/or elective courses. The study results suggested a total of 15 safety aspects to be acquired during undergraduate education. Results also indicated that $95 \%$ of the surveyed practitioners believe that all suggested safety aspects are important to very important. 
The authors recommend some modifications to enhance the current level of construction safety education in the MENA region. These enhancements include incorporating a core course at the senior level in the curriculum that is devoted to construction safety. In addition to construction safety topics, it is also suggested that topics related to DfCS should be included in traditional design courses in order to address this crucial issue in design courses.

\section{Bibliography}

1. Choudhry R.M. and Fang D. (2008). Why operatives engage in unsafe work behavior: Investigating factors on construction sites. Safety Sci. 46, 566-584.

2. Al-Humaidi H. M. and Tan F. H. (2010). Construction safety in Kuwait. J. Perf. Constr. Fac. 24, 70-77.

3. Davies V. J. and Tomasin K. (1996). Construction Safety Handbook. 2nd edition. Thomas Telford Publishing, London, pp 320. ISBN 072772519X

4. Choudhry R.M., Fang D. and Lingard H. (2009). Measuring safety climate of a construction company. J. Constr. Eng. Manage. 135, 890-899.

5. Maraqa M. A. and Mohamed A. O. (2013). Key drivers for successful safety management system of construction activities in Abu Dhabi Emirate. International Journal of Advanced Fire, Explosive, Environment Safety and Disaster Management 1(1), 1-17.

6. Szymberski R. (1997). Construction project safety planning. Technical Association of the Pulp and Paper Industry (TAPPI) Journal, 80 (11), 69-74.

7. Haupt T. C. (2003). The state of construction safety and health education at higher education institutions in the Western Cape of South Africa._ Special Issue article in: Construction Safety Education and Training - A Global Perspective, pp 1-10.

8. Pellicer E. and Molenaar K. R. (2009). Discussion of 'Developing a model of construction safety culture. J. Manage. Eng., 25(1), 44-47.

9. Suckarieh G. and Diamantes J. (1995). Educating construction management students in safety. Safety and Health in Construction, CIB Publication 209, Published by CIB Working Commission 99, pp. 154-164.

10. ACCE (2012). Standards and criteria for accreditation of postsecondary construction education degree programs, Document 103. American Council for Construction Education, San Antonio, Texas: http://accehq.org/documents/DOCUMENT103REVISIONS0712_000.pdf

11. Coble R.J., Hinze J.W., McDermott M.J., and Elliott B.R. (1999), Colleges' Emphasis on Construction Safety", in proceedings of the Second International Conference of CIB W99, Implementation of Safety and Health on Construction Sites, (Eds., Singh, Hinze and Coble), Balkema, Rotterdam, pp. 257-263.

12. Gambatese J. A. (2003). Safety emphasis in university engineering and construction programs. Special Issue article in: Construction Safety Education and Training - A Global Perspective, pp 1-15.

13. ABET (2012). 2013-2014 Criteria for Accrediting Engineering Programs. The Accreditation Board for Engineering and Technology. Engineering Accreditation Commission EAC, Baltimore, MD.

14. Al-Mufti M.A. (1999). Continuous enhancement of health and safety awareness in undergraduate civil engineering courses, in proceedings of the Second International Conference of CIB W99, Implementation of Safety and Health on Construction Sites, (Eds., Singh, Hinze and Coble), Balkema, Rotterdam, pp. 277-282.

15. Pellicer E., Seron J., Catala J., and Jorda L. (2003). Proposal of a new academic frame for the civil engineering education in construction safety and health. Proc., Int. Conf. on Engineering Education, July 21-25, Valencia, Spain.

16. Rubio M. C., Menendez A., Rubio J. C., and Martínez G. (2005).Obligations and responsibilities of civil engineers for the prevention of labour risks: References to European regulations. J. Profl. Issues Eng. Educ. Pract., 131(1), 70-75.

17. Cortes J. M., Pellicer E., and Catala J. (2012). Integration of occupational risk prevention courses in engineering degrees: Delphi study. J. Professional Issues in Engineering Education \& Practice 138(1), 31-36.

18. ManuelF. A. (1997). On the practice of safety, Wiley, New York.

19. Reese C. D. and Eidson J. V. (2006). Handbook of OSHA construction safety and health, 2nd Edition, Taylor \& Francis, Boca Raton Florida, USA. 
20. Toole T.M. (2004). Rethinking designers' roles in construction safety. Designing for safety and health in construction: Proc., Research and Practice Symposium, S. Hecker, J. Gambatese, and M. Weinstein (eds.), UO Press, Eugene, Ore.

21. Carpenter J.,Williams P., and Smith N.C. (2004). Identification and management of risk in undergraduate construction courses. Norwich: Health and Safety Executive, Report No. 275/2004.

22. Weinstein M., Gambatese J., and Hecker S. (2005). Can design improve construction safety?: Assessing the impact of a collaborative safety-in-design process. J. Construction Engineering and Management 131(10), 1125-1134.

23. Al Palumbo C. M. (2010). Safety in design: Enhancing construction safety by implementing safety in the design phase. CM eJournal. Retrieved from: http://cmaanet.org/files/files/SafetyInDesign060110.pdf 